\title{
Corporate Identity: Identifying Dominant Elements in CI Models
}

\author{
Jeremiah Iyamabo \\ Lagos Business School, Pan-African University \\ Km 22, Lekki-Epe Expressway, Ajah, Lagos, Nigeria \\ Tel: 234-810-323-5988Ｅ-mail: jiyamabo@lbs.edu.ng
}

Seyi Owolawi

Noah’s Ark Communications Limited, Lagos, Nigeria

Olutayo Otubanjo

Lagos Business School, Pan-African University, Lagos, Nigeria

Tosin Balogun

Lagos State University, Ojo, Lagos, Nigeria

Received: March 19, 2013 Accepted: April 18, 2013 Published: July 1, 2013

doi:10.5296/jmr.v5i3.3404 ～URL: http://dx.doi.org/10.5296/jmr.v5i3.3404

\begin{abstract}
Over the vast discourse on corporate identity (CI), several CI models have been proposed each with their respective elements, theoretical and empirical justifications for incorporating the corporate identity elements. These justifications are at the centre of where various scholars differ in the corporate identity debate. These dissenting positions notwithstanding, there are assenting points in the corporate identity debate. In an attempt to probe these areas, the authors re-examined the corporate identity debates and identified six critical CI models between 1995 and 2003. The cross-section of corporate identity elements from the models reviewed, revealed that six out of eight critical CI elements identified, attained a high level of agreement across corporate identity scholars. Finally, the authors recommend that further
\end{abstract}


study should focus on a wider scope of the corporate identity discourse for a more conclusive and verified result.

Keywords: Corporate identity, Corporate identity models 


\section{Corporate Identity (CI) Background}

The biggest and most valuable asset owned by any organization is its identity. The identity gives it a personality that determines the image and perception stakeholders have of the organization. Corporate identity is regarded as a strategic resource for building credibility and support amongst a variety of stakeholders and for gaining competitive advantage in any new business environment. It is widely accepted that corporate audiences rely on the reputation of firms coming out of their identities in making investment decisions, career decisions and product choices (Dowling, 1986). The identity of an organization dictates and influences how the external and internal publics view its actions and inactions, every organization has an identity the moment it opens its doors to service the public. From that instance the perception of the public is a reflection of the image propagated by its corporate identity. The corporate identity provides a unique identifier that reveals the organization's philosophy, personality and behaviour. This identity must be so clear that it becomes the yardstick against which its products and services, behaviour and (in)actions are measured (Olins, 1989). This means identity cannot simply be a slogan or name: it must be more; something visible, tangible and all embracing at the same time. Everything an organization does must be an affirmation of its chosen identity, a constant reflection of the governing ideals of the establishment.

Corporate identity emerged as a design concept and started to attract managerial interest as a design issue in the 1970s. This led to corporate identity being regarded as a strategic tool and source for competitive advantage (Bickerton, 1999). The edge needed to connect more with the consumers compared to the competition, with the appropriate corporate identity; organization's attain and maintain higher degree of relevance within the mind of the targets. According to Melewar \& Saunders (2000) an organization's corporate identity is composed of four sub-constructs: communication and visual identity; behaviour; corporate culture; and market conditions. This sub-construct adopts a multidisciplinary approach to the analysis of corporate identity, uniting the psychological, graphic, marketing and public relations paradigms of corporate identity. Although other authors have varied impressions of the constituting constructs of corporate identity, Melewar \& Saunders (2000) provide sound and well rounded arguments with their provision. Every construct of the corporate identity is further subdivided to provide integral components. Communication and visual identity is composed of (corporate communication, uncontrolled communication, architecture and location, corporate visual identity) and "behaviour" is made up of (corporate, employee and management behaviour). The corporate culture is also composed of (goals, philosophies and principles, nationality, organizational imagery and history) while the "market condition" sums up (nature and industry and corporate/marketing strategies).

Corporate visual identity (CVI), on the other hand, is a component of corporate identity. On its own, it does not make up a firm's holistic identity - only its visual identity. Melewar \& Saunders (1999) refer to it as the graphic design at the core of a firm's visual identity. Corporate visual identity is the outer sign of the inward commitment of a company (Abratt, 1989; Melewar \& Saunders, 2000). In other words, corporate visual identity is an assembly of visual cues by which an audience can recognize the company and distinguish it from others. Although the corporate visual identity of an organization is a component of its corporate 
identity, CVI is also made up of sub-components; name, symbol and/or logo, typography, colour, slogan and in most cases additional graphic elements.

The organization's colour of choice, its adopted typeface in creating its logo or crafting its slogan or shapes of choice; all these visual elements build an image or personality for every organization. In a society of myriad service providers, it is pertinent that every organization latches on to elements which make it stand out in a cluttered operational sphere. Although visual identity is important, it nonetheless remains only an aspect of corporate identity. Olins (1995) states that the purpose of the symbol is "to present the central idea of the organization with impact, brevity and immediacy". If an organization intends to make instant impressions on the minds of its targets, all visual offerings of the brand must also have phonological appeal (hence the need for slogans and memorable names).

Colours are very important in the passing of meaning and establishing significant associations - given their various interpretations in hue and intensity. The consumer often makes decisions based on cues or associations $\mathrm{h} /$ she can identify as a result of these elements. Coherence through consistency in CVI elements is a key factor in the reputation an organization develops over time. Regardless of how an organization decides to communicate its identity, whether in a monolithic, endorsed or branded form, it must ensure it has a unified voice. The colour, typeface, slogan, logo and name must all converge in communicated meaning. To become well regarded, companies must deserve it, by creating well rounded identities. They must develop coherent images and a consistency of posture internally and externally (Fombrun, 1996). From his observations, Fombrun argued that a link exists between the strength of a company's reputation and the consistency of its corporate identity. Against this background, a critical understanding of dominant corporate identity elements leading to reputation - based on studies by leading scholars would aid corporate identity construction and articulation.

\section{Key Elements in CI Models}

From the rich contributions in the corporate identity literature, emerges various models by leading scholars (e.g. Kennedy, 1977; Dowling, 1986; Abratt, 1989; Balmer, 1995; Markwick \& Fill, 1997; Stuart, 1998; 1999; Balmer \& Gray, 2000; Alessandri; 2001; Bick, Jacobson \& Abratt, 2003) each expressing how well the construct is to be conceptualized. Expectedly, these various approaches emerging from different schools of thought, have their points of divergence. It can therefore be said that conversely, corporate identity models would or should have their points of convergence - whereby these areas could point to a coherent understanding of where researchers of the subject are agreed. The purpose would be towards a more unified understanding of corporate identity and identification of the scholarly consensus - given the vast in the corporate identity literature representing asymmetrical divides on the subject (Olins, 1995; Bernstein, 1984; Balmer, 1998; Suvatjis \& de Chernatony, 2005; Cornelissen, Haslam \& Balmer, 2007). In reviewing the extant literature, eight models were chosen as the basis of analysis (i.e. Balmer, 1995; Markwick \& Fill, 1997; van Riel \& Balmer, 1997; Stuart, 1999; Alessandri, 2001; Bick, Jacobson \& Abratt, 2003). 


\section{Macrothink

These models are hereby analysed individually to identify the points of convergence and divergence in the corporate identity literature.

In Balmer's (1995) model, corporate identity begins at the corporate philosophy and corporate mission stage. The stance of the firm in terms of its philosophy will guide the personality of the firm which is a reflection of its culture. According to Balmer, this is what leads to the corporate identity - a projection and representation of what the firm is, what it stands for; its values, symbols, culture, etc. Based on this projection, and based on how its activities and responses to circumstances entail, the firm is perceived by its (customer-inclusive) stakeholders - which determines the corporate image. Balmer (1995) also incorporates a continuous feedback (communication) system with touch points on all key elements of the corporate identity process model such that the at the ownership (management) level (touch point 1, in Figure 1), management is able to maintain a relevance between its own conception and how it is conceived by its external publics.

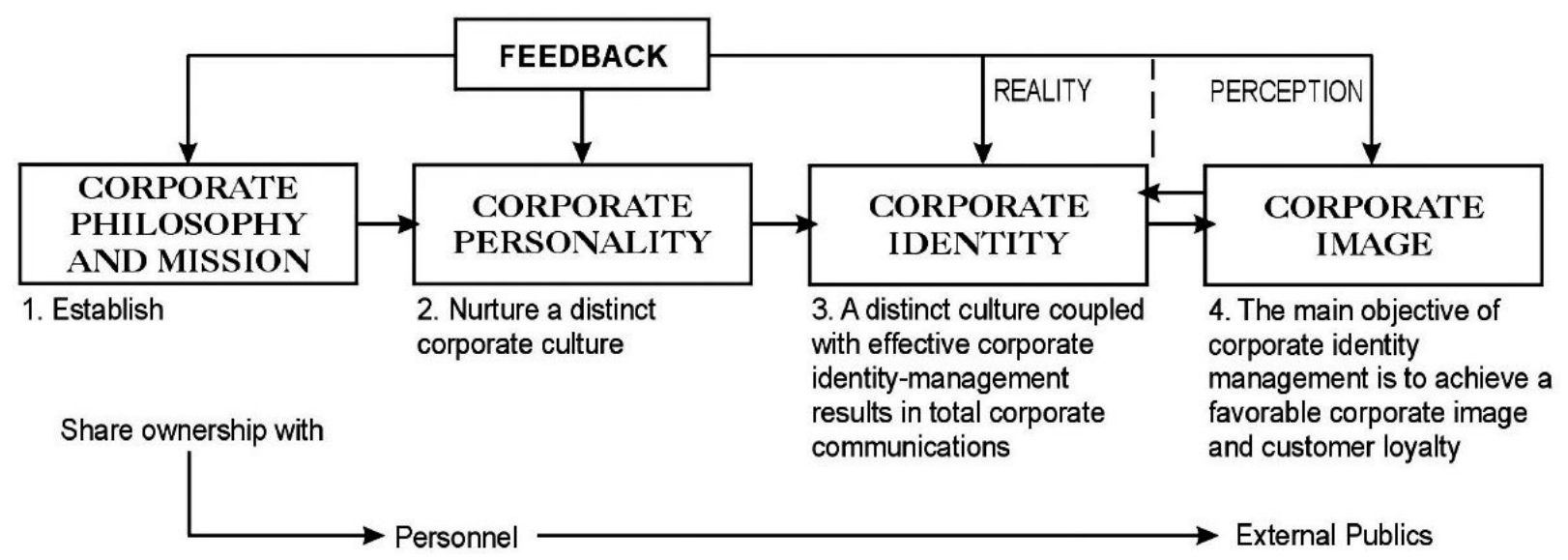

Figure 1. Corporate Identity Model (Balmer, 1995) 


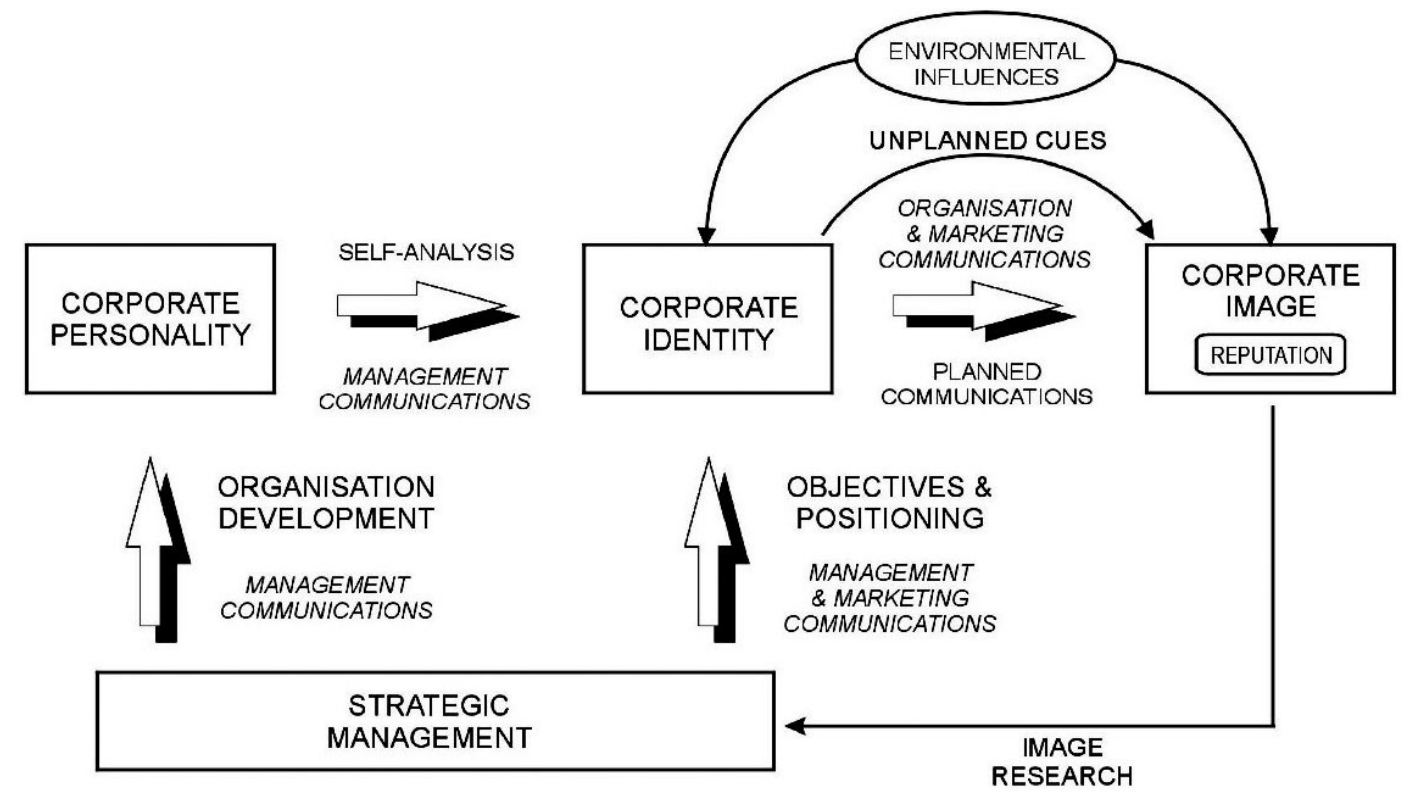

Figure 2. Corporate Identity Strategic-Management model (Markwick \& Fill, 1997)

Recognizing that for real brand building, the corporate personality and by extension, the corporate identity of the firm requires deep management involvement (see. Joachimsthaler \& Aaker, 1997), Markwick \& Fill (1997) infuse "strategic management” as a separate element determining corporate personality and “corporate identity”. They also extend the idea of the feedback mechanism proposed by Balmer (1995) by illustrating that it is a function of both deliberate and non-deliberate mechanisms. Deliberate communication processes which they term "planned communication" sums up the marketing communication efforts of the firm responsible for the image of the firm. Again, being a function of management, the perception of the firm is closely monitored by management such that negative environmental stimuli about the firm are received early enough by the firm's actors who have the required level of involvement to deal with such matters. The authors also suggest that "environmental influences" affect what how the firm defines itself (corporate identity) and how it is perceived by its external publics (corporate image and corporate reputation).

In van Riel \& Balmer's (1997) model, corporate reputation is disintegrated to reflect elements embedded in the construct (i.e. behaviour, communications and symbolism) as distinct from other elements involved in the corporate identity management process. The operating environment plays a more critical role as it affects every elements in the (corporate identity) management process - therefore, in this conceptualization, the role the environment plays has a much larger extension from Markwick \& Fill's (1997) model. The major contribution appears to be the inclusion of "organizational performance" and "corporate strategy" as a critical measurement factor for corporate identity. The authors argue that if corporate identity leads to corporate image and by extension, reputation (see. Balmer, 1995; Markwick \& Fill; 1997), in turn, corporate reputation, must be measured alongside other aspects of the firm (e.g. 
financial performance, sales, and human resource management).

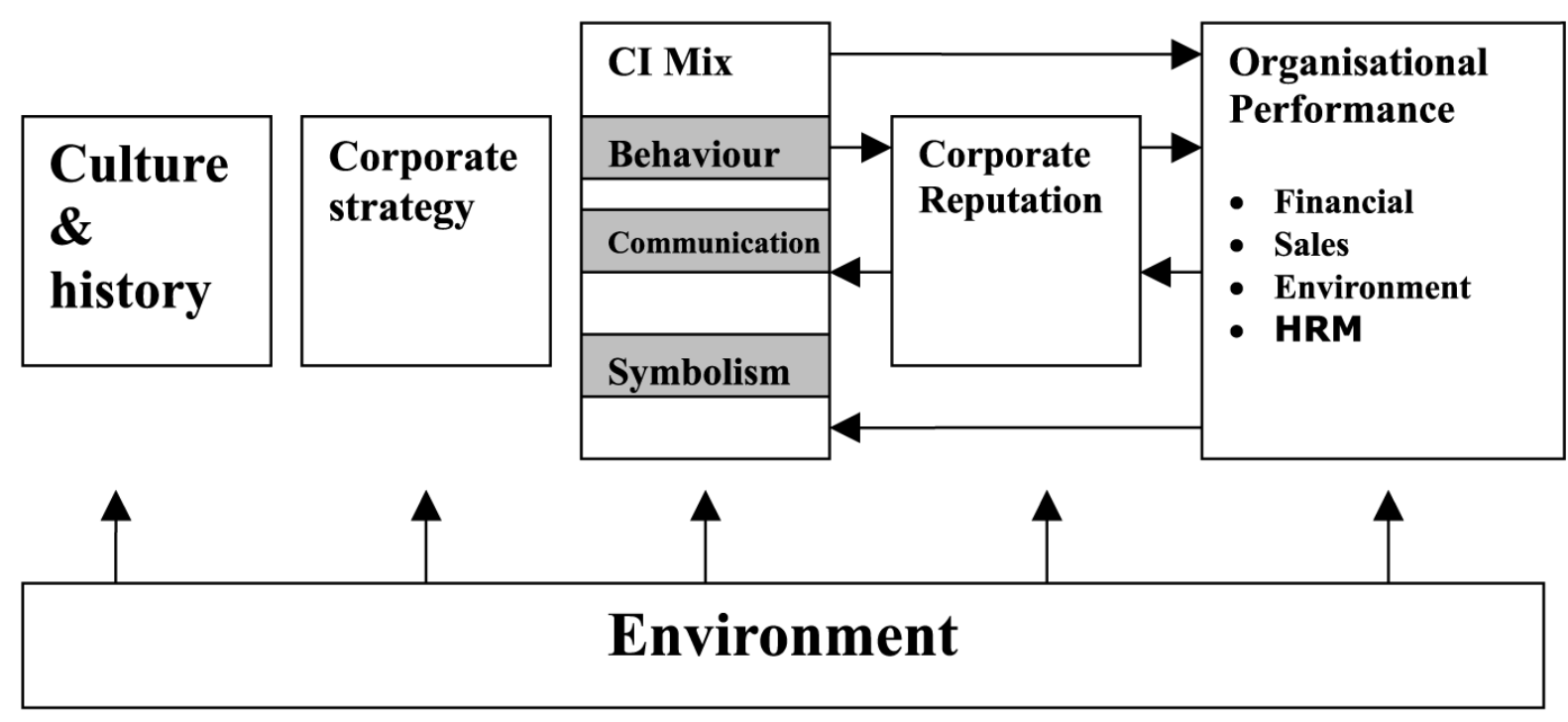

Figure 3. Corporate identity formation and performance model (van Riel \& Balmer, 1997)

Corporate strategy on the other hand is seen as an antecedent of corporate identity resulting from the cultural and historical background on which the firm is founded. Although the manner of interaction between the former and the latter is not specified in the model, the operating environment modifies what the corporate strategy is and how it evolves. Unlike Markwick \& Fill's (1997) model, van Riel \& Balmer omit how corporate personality plays out in the corporate identity management process. On the other hand, van Riel \& Balmer (1997) do not explicitly situate (marketing) communication in their model. Although, the element can be implied - just as it can be implied in any other model - it seems to be to integral to the corporate identity process to be omitted. Also, the model does not incorporate corporate image. The interaction between corporate identity and the firm's publics is only captured under the general description of “environment'; whereas, how corporate identity is operationalised through other elements before reaching the level of the external environment is not provided by this model. Instead, the focus seems to be on the internal processes for organizational performance.

Similar to van Riel \& Balmer (1997) Stuart (1999) identifies corporate strategy as an antecedent of corporate identity. However, the point of difference from van Riel \& Balmer (1997), corporate personality replaces the historic-cum-cultural background as the antecedent of corporate strategy. Instead, Stuart sees these three main elements of: corporate personality-leading to-corporate strategy-leading to-corporate identity as an all encompassing framework with organizational culture. Within that same framework, Stuart expands on the contribution of (van Riel \& Balmer, 1997) by decimating the components of corporate personality and corporate strategy. Following in the tradition of Schein (1990), culture 
therefore becomes the defining construct leading to corporate image and reputation through by marketing and interpersonal communication (i.e. similar to Balmer's deliberate and non-deliberate communicative processes). On all other grounds, (i.e. environment, corporate reputation, corporate image, marketing communication) the Stuart's model appears generically similar to the model proposed by van Riel \& Balmer (1997). In this model, the feedback (communicative) mechanism to ensure deep management involvement is more inclusive of all the encompassing elements.

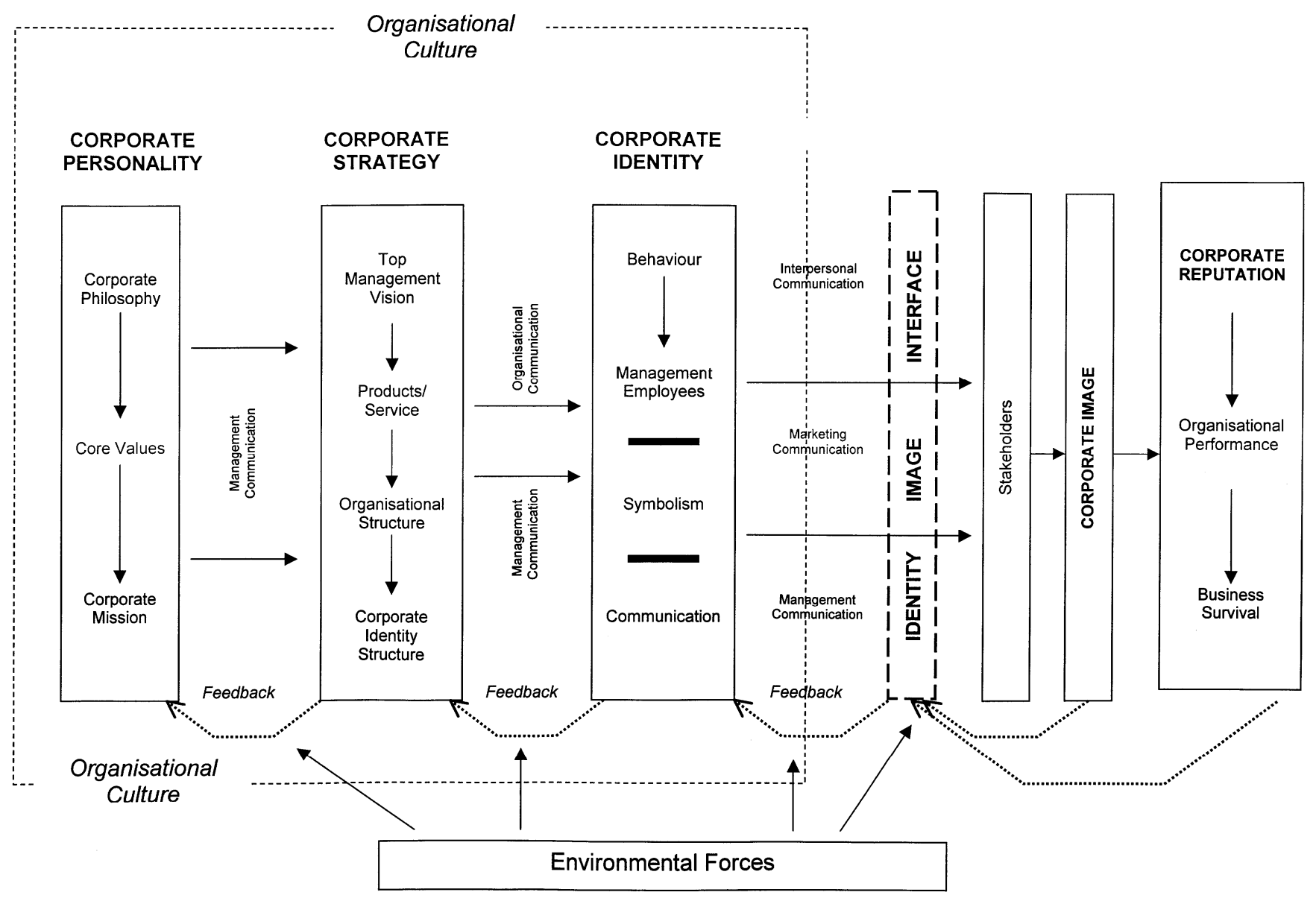

Figure 4. Corporate Identity Management Process model (Stuart, 1999)

The framework proposed by Alessandri (2001) appears generically similar to those proposed by Stuart (1999) and Markwick \& Fill (1997) from corporate identity to corporate reputation. The point of difference however, is found in the antecedents of corporate identity which Alessandri conceived as being informed by the corporate mission - driven through corporate behaviour and symbolic representation; whereas, van Riel \& Balmer (1997) and Stuart (1999) argue from the perspective of corporate strategy. Corporate behaviour on its part is an aspect of corporate culture since the inherent culture will determine the manner of response to (un)precedented circumstances. Incorporating “corporate mission”, therefore adheres to 


\section{Macrothink}

Balmer's (1995) conceptualization. Alessandri's (2001) model also clearly differentiates what is implicit in the earlier models (the firm's construction of itself versus how it is perceived by its intending stakeholders) and relies on theories in psychology as a way of explaining how the process of conditioning builds desired perceptions in the mind of key stakeholders. This however, is built from low-involvement (i.e. low-involvement theory) of consumers through the firm's (consistent) strong positioning and fulfillment of pleasurable experience(s) which the customers gain by aligning with the brand. By so doing, customers evolve into the phase of classical conditioning where nothing by the specific brand is desired.

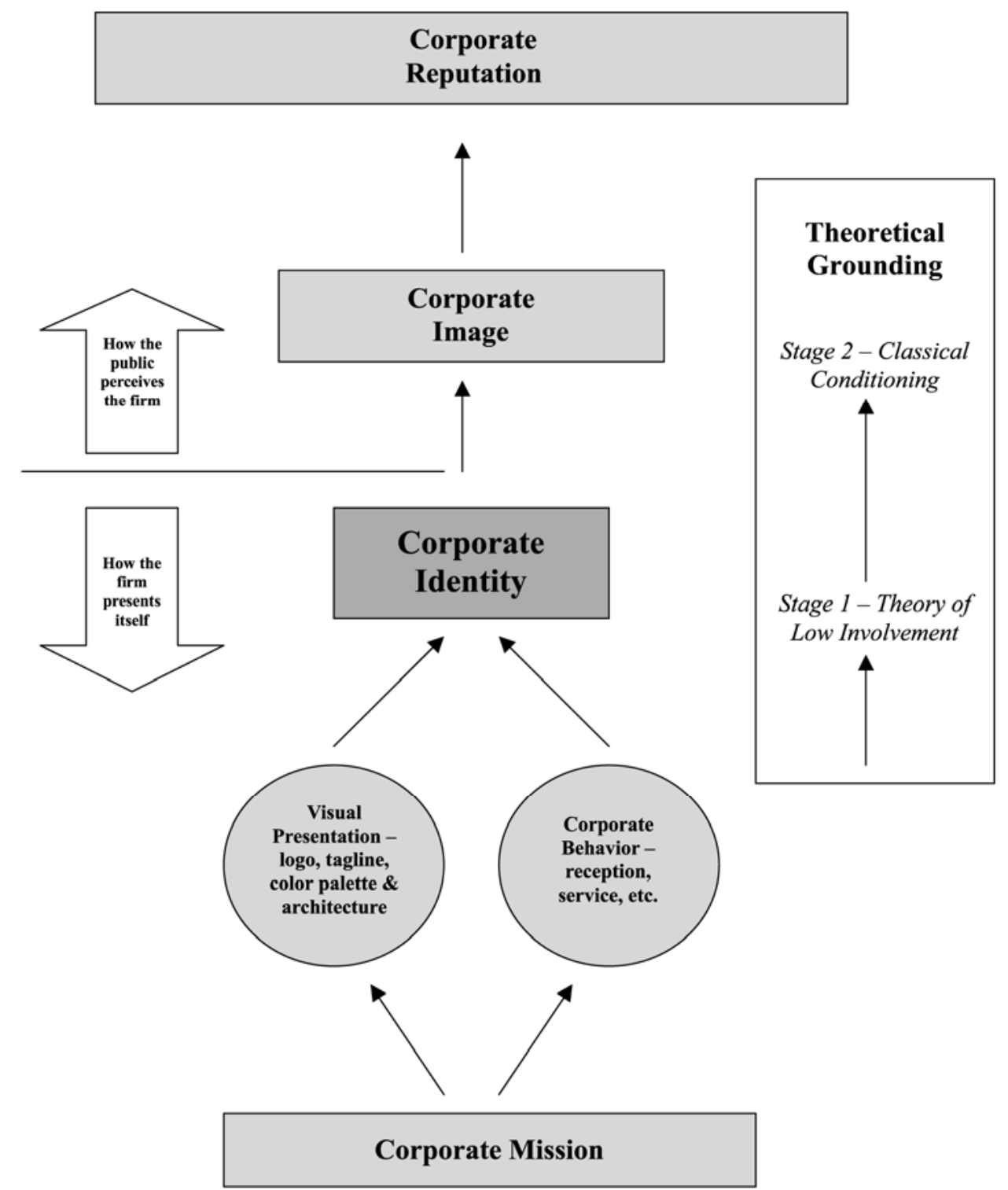

Figure 5. Corporate Identity Management Model (Alessandri, 2001) 


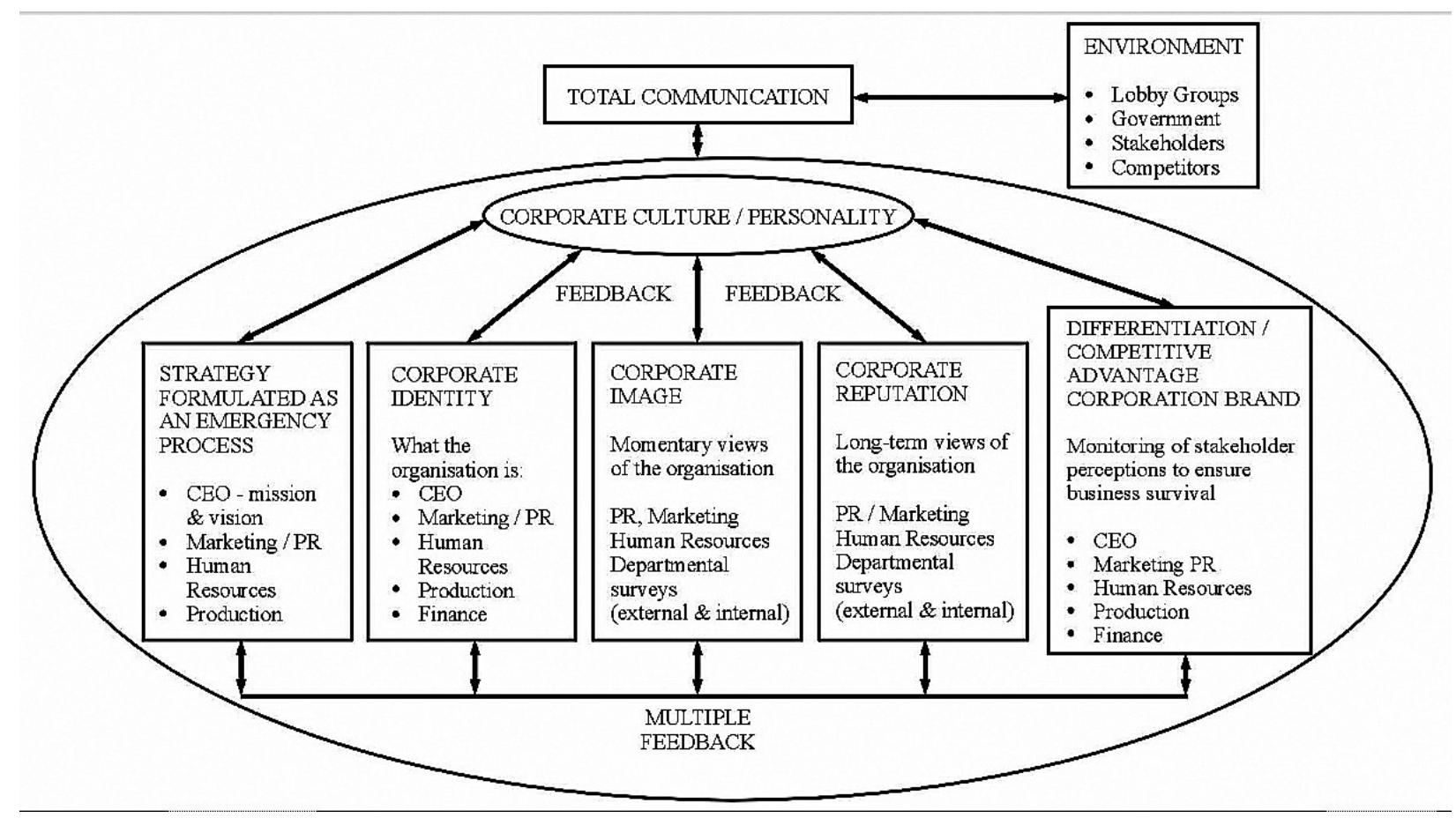

Figure 6. Bick, Jacobson \& Abratt’s (2003) model

Bick, Jacobson \& Abratt's (2003) model appears to integrate most of the elements of previous studies (i.e. mission, image, reputation, communication, culture, and environment). However, where the authors (Bick, Jacobson \& Abratt) distinguish their model is in the area of the interaction of these elements. Similar to Stuart (1999) culture again, becomes a central element in which all of the others are infused. Communication (i.e. total communication0 is also seen as an element which evolves through the entire process leading. In other words, all of the firm's activities in some way communicates its beliefs (philosophy), mission, identity, etc, to internal and external stakeholders, and for each of these elements, there is a high level of interactivity responsible for contributing to the communication process. On a holistic plane, the (total) communication is only a function of one variable - the operating environment in which the firm is located. The authors further elucidate the operatives of the enabling environment to include competitors, lobbyists, governmental control as well as other (salient) stakeholders. In essence, whatever the final, external communication portends, much take into consideration these operatives such that the firm becomes an enduring entity. Again, the two way relationship specified by the authors implies does not only imply that the total communication is a function of the operating environment as an extraneous entity, but also that the communication is constantly evolving to suit the every transforming nature of these sub-elements.

\section{Discussion}

The reviewed models above expatiate the different perspectives identified for consistently 


\section{Macrothink}

delivering what corporate identity and corporate visual identity are to organizations. An encompassing explanation is given as to why a level of consistence is important in organizational communication and Balmer's model provides a clear distinction between an organizations behavioural identity and its physical (visual) identity, the need to reach a midpoint between the two to connect with targets. Majority of the models also encouraged the mechanism of feedback, making sure the process never stops a continuous wave of back and forth flow to guarantee successful interaction. The models also highlight the importance/significance of symbolic representation in the need of an organization to achieve differentiation; the environmental meddling factors are also identified by van Riel \& Balmer's (1997) model. Alessandri's model integrates a psychological consideration into its explanation of the process model, laying emphasis on perception on two levels (low involvement and classical conditioning). The importance of a visual identity is also well stressed in Melewar \& Wooldridge (2001). It focuses on the need for reciprocity between the corporate identity and other determinants. The models ultimately at the end highlights the most important need for corporate identity and corporate visual identity as competitive advantage; establishing a reputation that gives preference to one firms offering over others.

Table 1. Key Elements in Selected Corporate Identity Models: 1995 - 2003

\begin{tabular}{|c|c|c|c|c|c|c|c|c|}
\hline & & 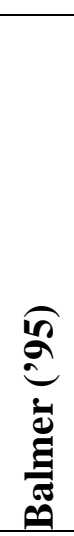 & 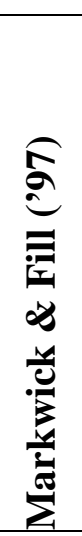 & 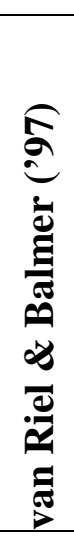 & 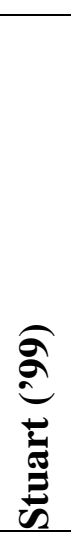 & 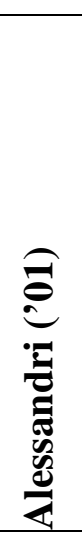 & 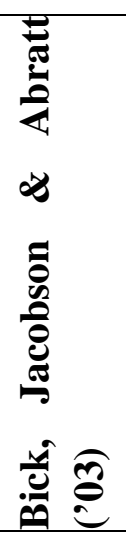 & Frequency \\
\hline 1. & $\begin{array}{l}\text { Corporate } \\
\text { Reputation }\end{array}$ & & $\checkmark$ & $\checkmark$ & $\checkmark$ & $\checkmark$ & $\checkmark$ & 5 \\
\hline 2. & Corporate Image & $\checkmark$ & $\checkmark$ & & $\checkmark$ & $\checkmark$ & $\checkmark$ & 5 \\
\hline 3. & Environment & & $\checkmark$ & $\checkmark$ & $\checkmark$ & & $\checkmark$ & 4 \\
\hline 4. & Feedback (Comm.) & $\checkmark$ & $\checkmark$ & & $\checkmark$ & & $\checkmark$ & 4 \\
\hline 5. & History & & & $\checkmark$ & & & & 1 \\
\hline 6. & $\begin{array}{l}\text { Mission } \quad \text { \& } \\
\text { Philosophy }\end{array}$ & $\checkmark$ & & & $\checkmark$ & $\checkmark$ & $\checkmark$ & 4 \\
\hline 7. & (Org.) Culture & $\checkmark$ & & $\checkmark$ & $\checkmark$ & & $\checkmark$ & 4 \\
\hline 8. & Org. Performance & & & $\checkmark$ & & & & 1 \\
\hline 9. & Personality & $\checkmark$ & $\checkmark$ & & $\checkmark$ & & $\checkmark$ & 4 \\
\hline 10. & $\begin{array}{l}\text { Strategic } \\
\text { Management }\end{array}$ & & $\checkmark$ & $\checkmark$ & $\checkmark$ & & $\checkmark$ & 4 \\
\hline
\end{tabular}


As shown in Table 1, (with the exclusion of corporate reputation and corporate image) four of the identified key corporate identity elements have the highest frequency

A major inadequacy of the models reviewed in this chapter, is that they are western-centric models, developed for application in a society functioning differently from the African/Nigerian economic/business clime. It is difficult to provide substantiated evidence that the models can or have been successfully applied in the Nigerian business environment. While majority of the models often clearly display a demarcation between the corporate identity and corporate visual identity of a corporation, in the Nigerian context most businesses consider an organization's corporate identity and symbolic representation as one and the same. Also majority of the models prioritize a feedback process, most organizational departments in the Nigerian economy run autonomously to an extent and rarely see the need for a consistent feedback. It may be considered as laborious and time wasting. Another point worthy of note is very few of the models were developed with reputation in mind as the focal issue to address. Rather, the models were focused on communication and environmental factors, but the effects of these actions or inactions on the reputation of an establishment was not dealt with.

In an attempt to identify the key corporate identity elements (corporate reputation and corporate image), two of the elements which are dominant in the literature were excluded. Scholars (e.g. Balmer, 1995; Fombrun, 1996; Fombrun \& van Riel, 1997) are already agreed that corporate image and by extension, reputation are implicit to the purpose of corporate identity and branding in the first place; whereas, the aim is to identify unique elements based on the contributions in the literature. From the review of six of the models in the literature, four papers report the same level of relevance (captured in the frequency column of Table 1) on five corporate key identity elements: environment, communication (feedback), mission and philosophy, organizational culture and personality. These elements indicate the level of relevance of across the literature. However, there is still the need to examine low frequency elements with the aim of identifying the strength of their contributions, to what extent other scholars (dis)agree with their contributions and finally, why these elements will record low frequency considering the level of extensive research involved in these studies. The low frequency elements are found in "history" and "organizational performance" (van Riel \& Balmer, 1997).

On a more fundamental level, the point of divergence seems to stretch between whether corporate identity is to be conceptualized as originating from culture or from the perspective of a corporate mission. Models such as Balmer (1995) and Alessandri (2001) point to corporate mission except that in the case of Balmer, it is fused with philosophy. However, it can be averred that philosophy is closely tied to culture - at least as long as philosophy continues to concern itself with conceptions of reality, knowledge (and categorization, thereof), values and approaches to reasoning. Hence, it continues to be a subjective discipline depending on the cultural constitution of the concerned individual, group or, in this case, organization. "Mission" (or "corporate mission") on the other hand, suggests a clear 
statement by an organization as to what it sets out to accomplish by asserting its purpose - i.e. why it exists and what it lives for - and the parties to benefit by its existence (Shee \& Abratt, 1989; David, 1989; Leuthesser \& Kohli, 1997). If therefore, the mission statement expresses the philosophy (therefore, culture) of the firm, would it be just then, to state the identity of the firm is found on its mission statement. Indeed, it would be trite to lay such a foundation on the underlying culture which will flesh out how the firm expresses who it says it is, and what it stands for, etc. This explains why this underlying culture and philosophy, Markwick \& Fill (1997), conceive as a strategic management function. Indeed, while the firm remains a mental-foetus, the prospective-management must invest deep thinking into determining what fundamental philosophies and from what cultural perspective(s), the firm will be grounded.

\section{Summary \& Conclusion}

From the cross-roads of elements in corporate identity models (see Figure 1), eight elements stand out from the key models cited in the literature. These studies are drawn from a period close to a decade. Irrespective of the acknowledgement that the elements captured in these models are not exhaustive - as models developed by current and later scholars may reveal other relevant corporate identity models - the results of this identification process indicates enduring elements which the current or future firm may want to take into consideration when constructing the identities of their organizations. To recapitulate, this study began by enumerating the importance of corporate identity construction and how it leads to positive corporate image and eventually, reputation. Following this, selected corporate identity models in the literature were reviewed. The models were chosen for review and discussion based on the perceived level of prominence in terms of references by other scholars as well as the value judgements of the authors - based on models which indicated a significant level of deviation from other established authors. Following this process, six of these models were chosen as discussed in Section 2 - 3 of this paper. In order to identify and reveal the points of confluence and divergence, the elements found in the selected works were tabulated vis-à-vis their respective authors to find out which element(s) had the highest frequency.

As mentioned earlier, elements (1) and (2) of Table 1, were set aside from elaboration based on the consensus in the literature; that is, they are inherent to the very purpose and processes of corporate identity. "Environment" as a corporate identity element, however, indicates high relevance across four models (Markwick \& Fill, 1997; van Riel \& Balmer, 1997; Stuart, 1999; Bick, Jacobson \& Abratt, 2003). These scholars point to the strong effect the operating environment bears on the firm. Bick, Jacobson \& Abratt (2003), expatiate on these elements to indicate the political mix (e.g. lobbyists) inherent in the operating environment. Just as in the strategic marketing literature where it has been established that the (political) environment bears on strategic planning, the same applies to the corporate identity literature where the identity has to be carefully constructed such that misconstrued meanings are not ascribed to the brand. This may affect the brand on the level of industry regulators and the bodies involved with policy formulation and reviews.

Also, if the brand is to accept that we live in a politically engineered world, the construction and construing of meaning (whether of symbols, values, motives, etc) would attain a much 
higher plane of relevance. In another sense, brand (corporate) identity cannot possibly exist without brand associations - which have very different levels of meaning. While the literature has demonstrated that brands are careful about their brand associations (whether such associations are other firms operating within or outside a given industry, or causes), brands also choose to openly associate and advocate policies which may well reflect and/or trigger causes. Take for instance, a national policy framework providing support for people living with autism with the sponsorship, support and proactive involvement of a financial institution; such an association is the result of the conscious effort of the brand custodians of both the financial institution and the governmental body mitigating the policy - say, the Ministry of Health, for instance, which would not want the project to be associated with a bank battling bad financial reputation. This level of collaboration will survive early stages of discussion (how much more, actualization) if only at the early stages, the constructed identity of both players and the interpretations thereof, are in accord.

For corporate personality, the arguments tend towards a consistent shift. Perhaps, this consistent shift explains its high frequency performance across the models under study. On the first front, is the argument that corporate personality is based on the personality of its founder - something sort of the "strong man" syndrome. As such, the founder bears his personality on the firm which may be "leadership”, "strength”, and "vigour”, for instance. On the other side, is the argument that the cultural mix of the firm representing the sub-cultures of the employee force, gives the firm a unique personality. Whatever the point of argument, what is quite obvious is an inter-relatedness between "personality" on one hand and "philosophy" and "culture" on the other - if we consider that the general, guiding philosophy will inform and determine the attitudinal presence of the firm. The arguments of how culture and philosophy guide the firm's identity from a foundational premise have already been discussed in Section 3 of this paper. Indeed, it is crucial that corporate personality and corporate identity continues to be harnessed by strategic management; whether that is articulated as "strategic management” or "corporate strategy" (Markwick \& Fill, 1997; van Riel \& Balmer, 1997, Stuart, 1999; Bick Jacobson \& Abratt, 2003).

What appears to be left out is the feedback process aspects of the models (Balmer, 1995; Markwick \& Fill, 1997; Stuart, 1999; Bick, Jacobson \& Abratt, 2003) which does not need extensive elaboration, again, since the brand building process itself is a communicative process. In conclusion, what this study demonstrates is that six out of eight unique elements have the same level of agreement across the literature. As discussed above, as relevant as "history" is to the corporate identity process, it does not appear to resonate across the models/authors possibly because history, again, is embedded in culture. The organizational performance model (van Riel \& Balmer, 1997), on the other hand, tends to shift towards internal management processes for desired outcome. Future studies may explore a wider scope of corporate identity models to bring the results up to date and to achieve a more conclusive result on the key elements across corporate identity models.

\section{References}

Abratt. (1989). A new approach to the corporate image management process. Journal of 
Marketing Management, 5(1), 63-76. http://dx.doi.org/10.1080/0267257X.1989.9964088

Alessandri, S.W. (2001). Modeling corporate identity: a concept explication and theoretical explanation. Corporate Communications: An International Journal, 6(4), 173-182. http://dx.doi.org/10.1108/EUM0000000006146

Balmer, J. M. T. (1995). Corporate branding and connoisseurship. Journal of General Management, 21, 22-46.

Balmer, J.M.T., \& Gray, E.R. (1999). Corporate identity and corporate communications: creating a competitive advantage. Corporate Communications: An International Journal, 4(4), 171-176. http://dx.doi.org/10.1108/EUM0000000007299

Balmer, J. M. T. (1998). Corporate identity and the advent of corporate marketing. Journal of Marketing Management, 14, 963-96. http://dx.doi.org/10.1362/026725798784867536

Bickerton, D. (1999). Corporate Marketing: rediscovering Drucker's lost agenda for marketing. International Centre for Corporate Identity Studies Working Paper Series, 99(4).

Bernstein, D. (1986). Company image and reality: A critique of corporate communications. London: Holt, Rinehart and Winston.

Bick, G., Jacobson, M. C., \& Abratt, R. (2003). The corporate identity management process revisited. Journal of Marketing Management, 19(7-8), 835-855. http://dx.doi.org/10.1080/0267257X.2003.9728239

Cornelissen, J. P., Haslam, S. A., \& Balmer, J. M. T. (2007). Social identity, organizational identity and corporate identity: towards an integrated understanding of processes, patternings and products. British Journal of Management, 18, 1-16. http://dx.doi.org/10.1111/j.1467-8551.2007.00522.x

Dowling, G.R. (1986). Managing your corporate images. Industrial marketing management, 15(2), 109-115. http://dx.doi.org/10.1016/0019-8501(86)90051-9

David, F.R. (1989). How companies define their mission. Long Range Planning, 22(1), 90-97. http://dx.doi.org/10.1016/0024-6301(89)90055-1

Fombrun, C., \& van Riel, C. (1997). The reputational landscape. Corporate Reputation Review, 1-16.

Fombrun, C. J. (1996). Reputation: Realizing value from the corporate image. Harvard Business Press.

Joachimsthaler, E., \& Aaker, D. A. (1997). Building brands without mass media. Harvard Business Review, 75, 39-41.

Kennedy, S.H. (1977). Nurturing corporate images: total communications or ego trip? European Journal of Marketing, 11, 120-64. http://dx.doi.org/10.1108/EUM0000000005007

Leuthesser, L., \& Kohli, C. (1997). Corporate identity: the role of mission statements. Business Horizons, 40(3), 59-66. http://dx.doi.org/10.1016/S0007-6813(97)90053-7 
Markwick, N., \& Fill, C. (1997). Towards a framework for managing corporate identity. European Journal of Marketing, 31(5/6), 396-409. http://dx.doi.org/10.1108/eb060639

Melewar, T.C. \& Wooldridge, A.R. (2001). The dynamics of corporate identity: a review of a process model. Journal of Communication Management, 5(4), 327-340. http://dx.doi.org/10.1108/13632540110806866

Melewar, T.C., \& Saunders, J. (2000). Global corporate visual identity systems: using an extended marketing mix. European Journal of Marketing, 34(5/6), 538-550. http://dx.doi.org/10.1108/03090560010321910

Melewar, T.C., \& Saunders, J. (1999). International corporate visual identity: standardization or localization?. Journal of International Business Studies, 583-598. http://dx.doi.org/10.1057/palgrave.jibs.8490084

Olins. (1989). Corporate Identity: Making Business Strategy Visible through Design. London: Thames and Hudson.

Olins, W. (1995). The new guide to identity. Aldershot: Gower

Schein, E. H. (1990). Organizational culture. American Psychologist, 45(2), 109. http://dx.doi.org/10.1037/0003-066X.45.2.109

Shee, P.S.B., \& Abratt, R. (1989). A new approach to the corporate image management process. Journal of marketing management, 5(1), 63-76. http://dx.doi.org/10.1080/0267257X.1989.9964088

Stuart, H. (1998). Exploring the corporate identity/corporate image interface: An empirical study of accounting firms. Journal of Communication Management, 2(4) , 357-371. http://dx.doi.org/10.1108/eb023476

Stuart, H. (1999). Towards a definitive model of the corporate identity management process. Corporate Communications, 4(4) , 200. http://dx.doi.org/10.1108/13563289910299328

Suvatjis, J. Y., \& de Chernatony, L. (2005). Corporate identity modeling: a review and presentation of a new multi-dimensional model. Journal of Marketing Management, 21, 809-834. http://dx.doi.org/10.1362/026725705774538480

Van Riel, C. B. M., \& Balmer, J. M. T. (1997). Corporate identity: the concept, its measurement and management. European Journal of Marketing, 31, 340-355. 